\title{
ANTHROPOMETRIC INDEX FOR PECTUS EXCAVATUM
}

\author{
Eduardo Baldassari Rebeis ${ }^{1}$, José Ribas Milanez de Campos², Ângelo Fernandez², \\ Luíz Felipe Pinho Moreira ${ }^{3}$, Fabio B. Jatene ${ }^{3}$
}

Rebeis EB, Campos JRM, Fernandez A, Moreira LFP, Jatene FB. Anthropometric index for pectus excavatum. Clinics. 2007;62(5):599-606.

BACKGROUND: Pectus excavatum (PEX) is a depression of the sternum in relation to the costal cartilages. Clinical and objective measures for classifying the defect are rare and difficult to apply. The present study aimed to create an anthropometric index (AI) for PEX as a method for diagnosis and for preoperative and postoperative assessment by comparing it to the Haller index (HI) and to the lower vertebral index (LVI).

METHODS: From December 2001 to February 2004, 2 groups of patients were studied at our institution: a) 30 patients with normal configuration of the thoracic cage, upon physical examination; b) 20 patients with PEX. The latter underwent surgery according to the Ravitch technique modified by Robicsek, and they were evaluated in the postoperative period. All patients were assessed by means of the AI (clinical), HI (tomographic), and LVI (radiographic) measures at the level of deepest deformity in the case of the PEX patients, and in the distal third of the sternum in the normal patients. The patients who had undergone surgery were once again measured between the 60th and the 80th postoperative days.

RESULTS: There was a high correlation between the AI and the HI $(80 \% P<.001)$ and between the AI and the LVI (79\% $P<$ $.001)$. The accuracy of the 3 indices was similar, in that the following cut points were established: AI $=0.12, \mathrm{HI}=3.10$, and LVI $=0.25$. Upon analyzing the preoperative results, we verified that for the 3 indices, over $75 \%$ of the patients with pectus excavatum were above the cut points and were confirmed as having the defect. In the postoperative results, the value of the indices found below the cut point was considered within the normal standard, and this occurred in $100 \%$ for the AI, in over $50 \%$ for the HI, and in $50 \%$ for the LVI.

CONCLUSIONS: The AI allowed adequate measurement of the defect, maintaining a) a high correlation with the HI and the LVI and a high accuracy, similar to the already acknowledged and published indices and b) an efficient comparison between the preoperative measurement and the postoperative results.

KEY-WORDS: Anthropometry/methods. Thoracic wall/abnormalities. Funnel chest/diagnosis. Funnel chest/surgery. Follow-up.

\section{INTRODUCTION}

Since the 15 th century, congenital deformities of the thoracic wall have been described and discussed in the lit-

1. Thoracic Surgery Service, Hospital das Clinicas, University of São Paulo, São Paulo, SP, Brazil.

2. Surgery Hospital das Clínicas, São Paulo University Medical School - São Paulo/SP, Brazil

3. Surgery- Heart Institute (INCOR), São Paulo University Medical School

- São Paulo/SP, Brazil

E mail: eduardo.rebeis@merconet.com.br

Received for publication on June 28, 2007

Accepted for publication on July 25, 2007 erature. ${ }^{1}$ The malformations of the anterior thoracic wall can be classified as deformities caused by the abnormal skeletal structure growth that is secondary to the incomplete fusion of the sternal blades, Poland's syndrome, and mixed or complex lesions of the dorsal column and costal arches. ${ }^{2}$ Within the defects related to abnormal cartilage growth, pectus excavatum (PEX), or funnel chest is the most frequent deformity and is defined as the sinking of the lower or medium portion of the sternal region in the direction of the spinal column. ${ }^{3}$

Among the most important consequences of the deformity are the psychological issues, which cause patients not 
to go out in public and to avoid sports activities, relationships, and contact with their peers. Relevant psychological alterations have been described, among which are anxiety, difficulty in participating in social relationships, limited working capacity, reduction in tolerance to frustration, and depression. ${ }^{4}$

The treatment of PEX accepted by most authors is surgical treatment, ${ }^{5,6}$ and indication for treatment is based on functional findings, ${ }^{3}$ psychological findings, ${ }^{4}$ the patient's quality of life findings, ${ }^{7}$ and aesthetic reasons. ${ }^{8}$

Few studies have objectively classified the degree of anatomic distortion to enable the quantification of the depression of the anterior thoracic wall, the comparison of groups, and the assessment of postoperative results. ${ }^{9}$ In general, the assessment of these patients has been carried out only subjectively during clinical inspection. ${ }^{10}$ The objective evaluations found in the medical literature ${ }^{9,11-19}$ are still not consensual, either due to the complexity of the measurements or to conceptual controversies. The objectives of this study were a) to propose an index that is easy to apply for measuring PEX and to compare it with the Haller index and to the lower vertebral index; b) to enable comparison between the groups of patients of the preoperative and postoperative periods, thus allowing the surgical results obtained to be evaluated concretely and objectively.

\section{METHODS}

From December 2001 to February 2004, 20 patients with PEX and 30 patients with a thorax considered morphologically normal were studied at the Thoracic Surgery Service, of the Hospital das Clínicas, School of Medicine, University of São Paulo. The criteria for inclusion of patients with PEX were as follows: a) during the physical examination, the presentation of the depression of the central portion of the anterior thoracic wall in relation to the adjacent costal cartilage; b) discontentment with the defect of the anterior thoracic wall; c) age ranging from 8 to 40 years; and d) body mass index lower than $25 .{ }^{20}$ The following patients were excluded: a) patients with mammary implants; b) breastfeeding patients; c) patients with no clinical conditions for surgery; and d) presence of affections that might increase surgery morbidity. The patients with PEX ranged in age from 9 to 31 years (mean, 16.3 years); 14 were male $(70 \%)$ and 6 were female $(30 \%)$. The criteria for inclusion of normal patients were as follows: a) absence of depression or protusion of the central portion of the anterior thoracic wall in relation to the costal cartilage during physical examination; b) recent radiography and CT scan of the thorax due to another type of clinical investigation; c) age ranging from 8 to 40 years; and d) body mass index lower than 25. Patients excluded included patients with any affection that might interfere in the normal morphology of the thoracic cage. Normal patients (30) were included with ages ranging from 15 to 36 years (mean, 24 years); 22 were male (73\%) and 8 were female $(27 \%)$.

The sample was evaluated according to the clinical ${ }^{14}$ measurements of the external thorax and tomographic ${ }^{16}$ and radiographic ${ }^{18}$ configuration, which were always carried out by the same examiner at the level of maximum deformity (MD) in the case of patients with PEX, or in the lower third of the sternum (TD) in the case of patients with a morphologically normal thorax. The patients with a thoracic deformity underwent surgical correction and once again were measured between the 60th and 80th postoperative days.

The A and B clinical measurements were carried out with the patient in a horizontal supine position on a flat table parallel to the floor during deep inhalation. (Figures 1, 2, and 3). The A measurement was defined as the largest anteroposterior diameter at the level of the distal third of the sternum, and the B measurement was the largest depth at the same level. The anthropometric index (AI $)^{14}$ for PEX was defined as the B measurement divided by the A measurement $(\mathrm{AI}=\mathrm{B} / \mathrm{A})$.

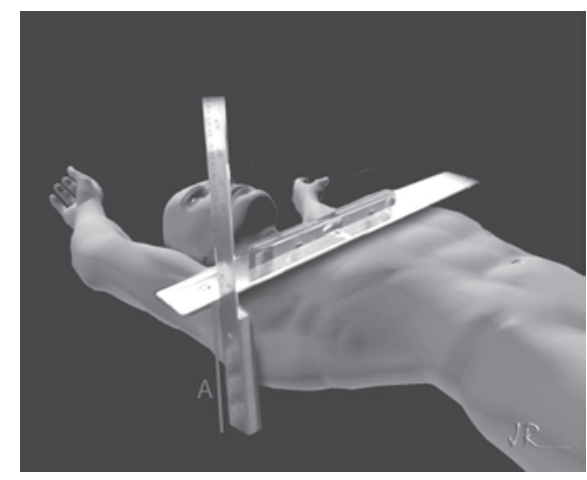

Figure 1 - A Measurement = anteroposterior distance during deep inhaling, at the distal third of the sternum.

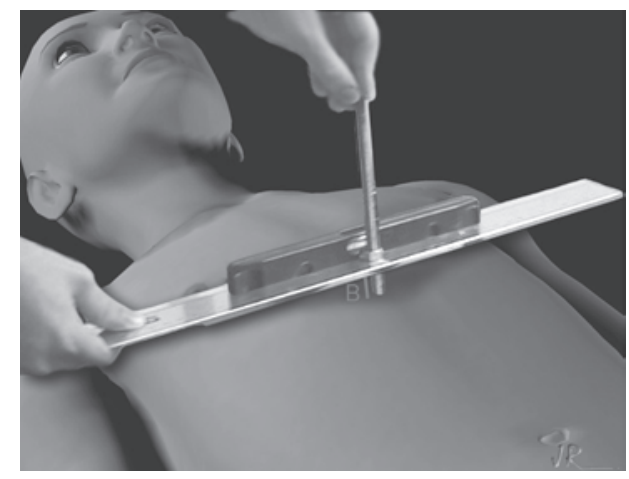

Figure 2 - B Measurement = greater depth at the distal third of the sternum 
The tomographic measurements were obtained from the slice of the mediastinal window as follows: with the greatest latero-lateral distance (A measurement) and the shortest anteroposterior distance ( $\mathrm{C}$ measurement). The Haller index $(\mathrm{HI})^{16}$ is the ratio between the $\mathrm{A}$ measurement and the $\mathrm{C}$ measurement $(\mathrm{HI}=\mathrm{A} / \mathrm{C})$. (Figure 3$)$.

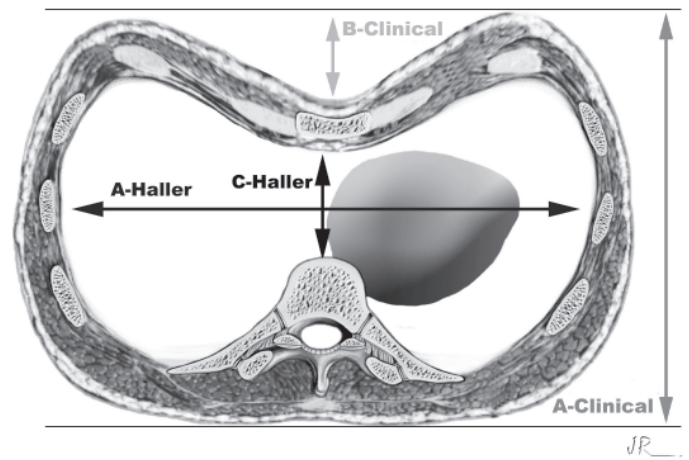

Figure 3 - Anthropometric index $=\mathrm{B}$ clinical $/ \mathrm{A}$ clinical $(\mathrm{B}=$ depth of the deformity; A = anteroposterior distance. Haller Index = A Haller / C Haller ( $\mathrm{A}=$ maximum latero-lateral distance; $\mathrm{C}=$ shortest anteroposterior distance. Both the indices calculated at the distal third of the sternum.

The radiographic measurements were obtained from the simple thorax radiography, where the $\mathrm{BC}$ measurement was equal to the sagittal diameter of the vertebra, and the $\mathrm{AC}$ measurement referred to the sagittal anteroposterior diameter of the posterior board of the sternum to the posterior portion of the vertebral body. The lower vertebral index $(\mathrm{LVI})^{18}$ was defined as the ratio between $\mathrm{BC}$ and $\mathrm{AC}$, (LVI $=\mathrm{BC} / \mathrm{AC}$ ) (Figure 4).
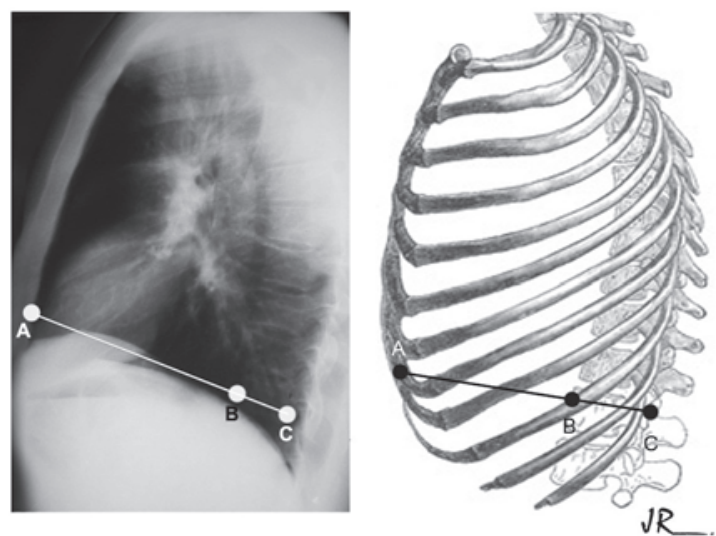

Figure 4 - Schematic representation of the lower vertebral index (LVI). BC= vertebral sagittal diameter and $\mathrm{AC}=$ diameter of the posterior board of the sternum to the posterior portion of the vertebral body. $\mathrm{LVI}=\mathrm{BC} / \mathrm{AC}$

The patients with PEX underwent surgical correction. The technique adopted was that of Ravitch ${ }^{21}$ modified by Robicsek et al. ${ }^{22}$

The proposed statistical study was as follows: sample distribution tests (KS normality test; D’Agostino \& Pearson normality test; Shapiro-Wilk normality test). The correlations between the AI versus the HI and the AI versus the LVI were calculated according to the Spearman test. The receiver-operating characteristic (ROC) curve between the patients with PEX and normal patients for the AI, the HI, and the LVI was determined. The comparisons between the preoperative and postoperative periods of the AI, the HI, and the LVI were determined by means of the Wilcoxon test with signed ranks. The GraphPad Prism 4.2 statistical program was used to calculate the statistical values. The level of significance considered was $P<.05$. This protocol was approved by the Institutional Ethical Committee for the Analysis of Research Projects.

\section{RESULTS}

There was no mortality in the sample of the patients who underwent surgery. The morbidity found was as follows: 1 patient with a rotavirus infection, 7 patients with the accidental opening of the right pleura with no need for closed pleural drainage, 3 patients with skin dehiscence, 2 patients with occipital seroma, 2 patients with partial pulmonary atelectasis, and 2 patients with pleural effusion.

The values found for the AI, the HI, and the LVI did not have symmetrical distributions, which led us to use nonparametric statistical tests to analyze our data. The mean values found for the PEX sample and the normal patient sample are shown on Table 1. Spearman's correlation test showed high correlation between the indices $(0.80, P$ $<.001$ for AI $x$ HI and $0.79, P<.001$ for AI $x$ LVI). Therefore, the AI is effective in the assessment of PEX.

Table 1 - Descriptive statistical analysis for patients with for pectus excavatum and normal patients, considering the AI, the HI, and the LVI

\begin{tabular}{lcccccc}
\hline & $\begin{array}{c}\text { Normal } \\
\text { AI }\end{array}$ & $\begin{array}{c}\text { PRE } \\
\text { AI }\end{array}$ & $\begin{array}{c}\text { Normal } \\
\text { HI }\end{array}$ & $\begin{array}{c}\text { PRE } \\
\text { HI }\end{array}$ & $\begin{array}{c}\text { Normal } \\
\text { LVI }\end{array}$ & $\begin{array}{c}\text { PRE } \\
\text { LVI }\end{array}$ \\
\hline Minimum V & 0.01 & 0.08 & 1.75 & 2.28 & 0.15 & 0.22 \\
P 25\% & 0.02 & 0.14 & 2.00 & 3.40 & 0.19 & 0.26 \\
Mean & 0.03 & 0.20 & 2.16 & 4.46 & 0.21 & 0.31 \\
P 75\% & 0.04 & 0.25 & 2.34 & 5.40 & 0.23 & 0.41 \\
Maximum V & 0.12 & 0.33 & 3.00 & 7.23 & 0.26 & 0.54
\end{tabular}

V, Value; P, Percentile; AI, anthropometric index; HI, Haller index; LVI, lower vertebral index; Normal, patients with normal thoracic cage; PRE, patients with pectus excavatum in the preoperative period.

By using the ROC curves for the 3 indices, the AI, the $\mathrm{HI}$, the LVI, separately in the PEX and normal groups, we found the curve areas and the cut points for the indices to prioritize the specificities. Above these cut points would be patients with pectus excavatum and below them, nor- 
mal individuals (Tables 2 and 3). A high accuracy of the $\mathrm{AI}$ is hence shown.

Table 2 - Values of the areas under the ROC curves and their respective confidence intervals for the AI, the $\mathrm{HI}$, and the LVI for pectus excavatum

\begin{tabular}{lccc}
\hline & Curve Area & Confidence Interval & $P$ \\
\hline AI & 0.99 & 0.96 to 1.01 & $<.001$ \\
HI & 0.96 & 0.92 to 1.01 & $<.001$ \\
LVI & 0.96 & 0.91 to 1.01 & $<.001$ \\
\hline
\end{tabular}

AI, anthropometric index; HI, Haller index; LVI, lower vertebral index

Table 3 - Values of the cut points for the AI, the HI, and the LVI for pectus excavatum, with the corresponding sensitivities and specificities

\begin{tabular}{lccc}
\hline & Value & Sensitivity & Specificity \\
\hline AI & 0.12 & $80 \%$ & $100 \%$ \\
HI & 3.1 & $85 \%$ & $100 \%$ \\
LVI & 0.25 & $80 \%$ & $96 \%$ \\
\hline
\end{tabular}

Value, cut point for the applied index; AI, anthropometric index; HI, Haller index; LVI, lower vertebral index

To compare the result between the preoperative periods and postoperative periods, we applied Wilcoxon's nonparametric test with signed ranks, where statistical difference was observed among groups for the $\mathrm{AI}$, the $\mathrm{HI}$, and the LVI with $P<.001$. The means, percentiles, and maximum and minimum values found in the descriptive statistical analysis and the cut points obtained from the ROC curves are shown in Figures 5, 6, and 7 for the 3 indices, respectively, where it was shown that the AI was the one that best expressed the transformations of the anterior thoracic cage after surgical correction.

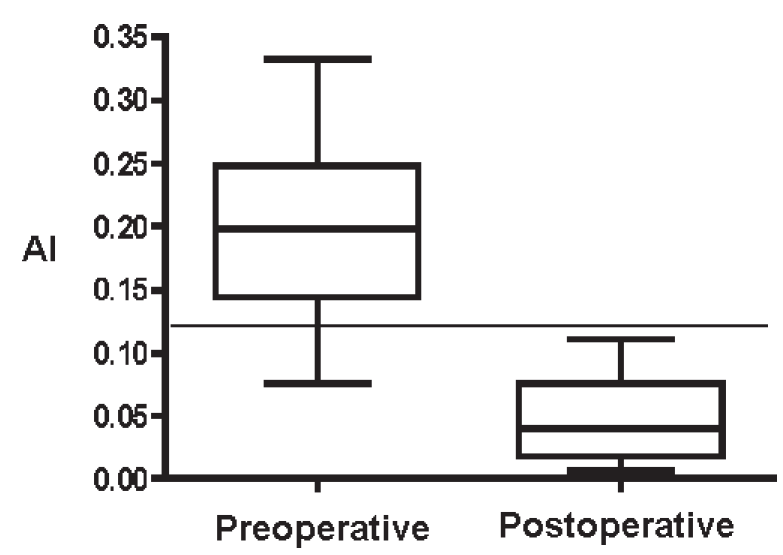

Figure 5 - AI: anthropometric index for pectus excavatum pre and postoperative; 0,12 , value adopted as cut point among patients with pectus excavatum and patients with normal thoracic configuration for the AI.

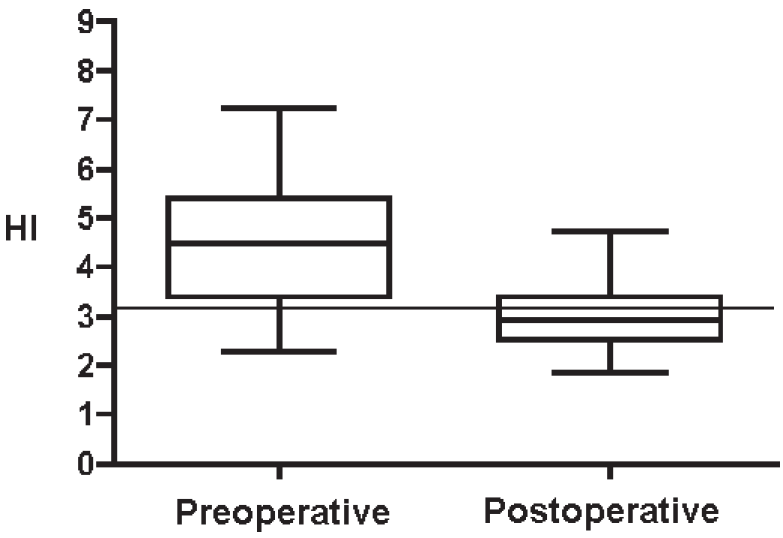

Figure 6 - HI: pre and postoperative Haller index; 3,1, value adopted as cut point among patients with pectus excavatum and patients with normal thoracic configuration for the HI.

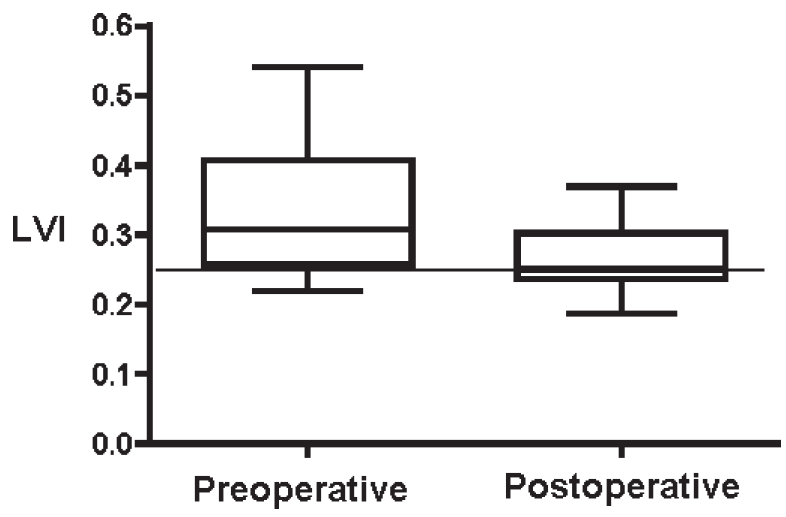

Figure 7 - LVI: pre and postoperative lower inferior index; 0,25, value adopted as cut point among patients with pectus excavatum and patients with normal thoracic configuration for the LVI.

\section{DISCUSSION}

Authors such as Welch, ${ }^{19}$ Backer et al, ${ }^{15}$ Hümmer and Willital, ${ }^{12}$ Haller et al, ${ }^{16}$ and Derveaux et al ${ }^{18}$ created indices to quantify the deformity and/or to enable the comparison between the preoperative and postoperative periods more objectively. However, the common point that can be observed in the previously described indices is that all of them are obtained with measurements that relate the approximation of the sternum to the thoracic column and not with the unevenness of the sternal region in relation to the costal cartilage in the direction of the column.

The internationally accepted $\mathrm{HI}$ is undoubtedly the most divulged assessment parameter among surgeons who treat this deformity. In the original study with 33 patients with PEX and 19 normal individuals, the cut point was 3.25 , above which the patients were classified as having moderate or severe PEX and were referred to surgery. Haller et $\mathrm{al}^{16}$ did not identify differences in the index regarding age. 
This publication was more recently refuted by Daunt et al, ${ }^{23}$ upon studying 557 patients where the HI was measured tomographically, showing that children under 2 years have a lower HI than older ones, and that women have a higher HI than men from 0 to 6 and from 12 to 18 years, thus showing statistical differences regarding age and gender.

In our sample, the HI cut point considered was equal to 3.10 , very close to the cut point of the original study, which was 3.25 . This small difference is possibly due to the fact that we prioritized the specificity of the HI in our material, whereas Haller et al $^{16}$ considered the sensitivity of the method a priority. We would like to emphasize that for the author, patients with an index higher than 3.25 were considered as having moderate or severe PEX with indication for surgery, and below this value, the patients would be in the range of patients with mild PEX or of normal individuals. The HI considers, in one of its measurements, the minimum internal anteroposterior distance of the sternum to the vertebral body, which causes this index not to reflect the specific deformity (the depression of the sternum in relation to the costal cartilage), but rather to reflect one of its consequences, because it values the approximation of the sternum to the column, which not always characterizes this deformity. In addition, this index does not consider the tissues that cover the sternum and that also participate in the aesthetics of the anterior thoracic wall.

In our sample, the cut point for the lower vertebral index of patients with PEX and of normal patients was equal to 0.25 , ie, within the means published by Derveaux et al. ${ }^{18}$ Likewise, as has already been discussed for the HI, the LVI also considers the sternovertebral sagittal distance in its composition and does not consider the tissues that cover the sternum, thus triggering the same concerns as those we discussed for the HI.

We value the AI, since it is the ratio of the measurements related to the external configuration of the thorax, and this immediately leads us to the cosmetic aspect of the thorax; the priority in this assessment is for the doctor to estimate the real aesthetic defect and not the bone deformity. This is a relevant issue, since the defect has strong aesthetic implications for the patient regarding the psychological scope..$^{4,24,25}$ The indices that are based on the internal configuration of the thorax, as is the case with the HI, the LVI, the frontosagittal index, ${ }^{15}$ and the Welch ${ }^{19}$ index, do not take into consideration the soft tissues that cover the thoracic skeleton and are related to the minimum sagittal anteroposterior distance of the posterior board of the sternum to the vertebral body.

Upon comparing the ROC curves of the 3 indices, it was noticed that the areas under the curves are large and similar $(\mathrm{AI}=99 \%$; $\mathrm{HI}=96 \%$, and LVI $=96 \%$ ), thus show- ing good accuracy in the diagnosis of PEX for all the indices tested. Upon associating the ROC curve for AI with the high correlation between the $\mathrm{AI}$ and the other indices applied in our sample, we can propose the equivalence of the AI to the indices already accepted in the literature, as is the case for the HI and the LVI, with the advantage that we do not need imaging methods for the diagnosis of PEX, and as has already been mentioned, we have been assessing the external (aesthetic) configuration of the patient.

Differences were found for the 3 indices upon the application of the Wilcoxon signed ranks test to the preoperative and postoperative results as follows: AI $(P<$ $.001)$; HI $(P<.001)$, and LVI $(P<.001)$. This statistically confirms that through surgical correction, our preoperative group is transformed into another group, the postoperative one, comprised of the same individuals, however, with another configuration that is aesthetically closer to normal.

The graphic representation of the descriptive statistics of the preoperative and postoperative periods for each index with the added cut point obtained from the ROC curve (Figures 5-7) showed similar results in the preoperative period for the 3 indices; thus, it can be stated that for our sample of patients with PEX in the physical examination, over $75 \%$ were confirmed as having PEX. In the postoperative period, it was shown that for the AI, the HI, and the LVI, the percentage of patients undergoing surgery who presented results within normal standards was $100 \%$, more than $50 \%$, and $50 \%$ respectively. Therefore, the AI can detect normality standards of the external configuration of the anterior thoracic wall not determined by the HI and the LVI.

The results obtained regarding the LVI are compatible with those of Ohno et al, ${ }^{26}$ who studied 47 patients with PEX and 210 normal children by means of assessments carried out with the LVI and concluded that this index improved in the postoperative period; however, it did not present normal values, particularly in thin patients with a flat thorax.

Based on our results, we are proposing the use of the AI as an objective assessment method of patients with PEX because of the following: a) the method is easy to apply and has high correlation with the HI and the LVI, as well as high accuracy in the diagnosis of PEX and b) it enables an effective comparison between the preoperative and postoperative periods for the patients with pectus excavatum treated surgically.

\section{ACKNOWLEDGMENTS}

To Prof. Dr. Carlos Tadeu dos Santos Dias (Department of Exact Sciences of Escola Superior de Agricultura Luiz 
de Queiroz [Esalq] - University of São Paulo-[USP]Piracicaba); To Prof. Dr. Lauro Kawabe (Responsible for Scheduling Surgeries at the Instituto do Coração - INCORFMUSP-São Paulo); To the doctors and employees of the
Thoracic Surgery Service of the Hospital das Clínicas FMUSP-São Paulo), To the Municipal Department of Health of Piracicaba; To the patients that took part in this study.
Rebeis EB, Campos JRM, Fernandez A, Moreira LFP, Jatene FB. Índice antropométrico para pectus excavatum. Clinics. 2007;62(5):599-606.

INTRODUÇÃO: O pectus excavatum (PEX) caracterizase por depressão do esterno em relação ao gradeado costal. Medidas clínicas e objetivas para classificar esse defeito são raras e de difícil aplicação. Este trabalho tem por objetivo criar um índice antropométrico para PEX (IA) como método diagnóstico e de avaliação pré e pós-operatória, comparando-o ao índice de Haller (IH) e ao índice vertebral inferior (IV).

MÉTODOS: No período de dezembro de 2001 a fevereiro de 2004 foram estudados dois grupos de pacientes no Serviço de Cirurgia Torácica do Hospital das Clínicas da Faculdade de Medicina da Universidade de São Paulo (HC-
FMUSP): a) 30 pacientes com a caixa torácica com configuração normal ao exame físico; b) 20 pacientes portadores de PEX. Estes últimos foram operados pela técnica de Ravitch modificada por Robicsek e pelo Serviço de Cirurgia Torácica do HC-FMUSP, sendo estudados no pós-operatório. Todos os pacientes foram avaliados a partir do IA (medidas clínicas), do IH (medidas tomográficas) e do IV (medidas radiográficas) no nível da maior deformidade (MD), no caso dos PEX e no terço distal do esterno (TD), nos normais. Os pacientes operados foram novamente medidos entre o $60^{\circ}$ e o $80^{\circ}$ dia do pós-operatório.

RESULTADOS: Houve elevada correlação entre o IA e o IH $(80 \%$ p $<0,001)$ e entre o IA e o IV $(79 \%$ p $<0,001)$. A acurácia dos três índices foi similar, sendo que se estabeleceram os seguintes pontos de corte: $\mathrm{IA}=0,12 ; \mathrm{IH}=3,10$; e IV $=0,25$. Ao ser analisado o pré-operatório, foi verifi- 
cado para os três índices, que mais de $75 \%$ dos portadores de PEX encontravam-se acima dos pontos de corte e foram confirmados como portadores do defeito. No pós-operatório os valores dos índices encontrados abaixo do ponto de corte foram considerados dentro do padrão normal e isso ocorreu em $100 \%$ para o IA, em mais de $50 \%$ para o $\mathrm{IH}$, e em $50 \%$ para o IV.

CONCLUSÕES: O IA permitiu mensurar adequadamen- te o defeito, mantendo: a) alta correlação com o IH e o IV e elevada acurácia, semelhante à desses índices já consagrados; b) eficaz comparação entre o pré e pós-operatório.

UNITERMOS: Antropometria/Métodos. Parede Torácica/ Anormalidades. Tórax em Funil / Diagnóstico.Tórax em Funil/Cirurgia Seguimentos.

\section{REFERENCES}

1. Haller JA. Operative management of chest wall deformities in children: unique contributions of southern thoracic surgeon. Ann Thorac Surg. 1988;46:4-12.

2. Campos JRM, Filomeno LTB, Fernandez A. Deformidades congênitas da parede torácica. In: Pneumologia- Atualização e Reciclagem. Sociedade Paulista de Pneumologia e Tisiologia. Vol III. São Paulo, 1999.

3. Trench NF, Saad R. Tórax infundibular e carinado. In: Trench NF, Saad R. Cirurgia torácica. São Paulo: Panamed; 1983. p. 81-124.

4. Einsiedel E, Clausner A. Funnel chest. Psychological and psychosomatic aspects in children youngsters and young adults. J Cardivasc Surg. 1999;40:733-6.

5. Humphreys GH II, Jaretzki A III. Pectus excavatum late results with and without operation. J Thorac Cardiovasc Surg. 1980;80:686-95.

6. Campos JRM de, Fonseca MH, Werebe E de C. Technical modification of the Nuss operation for the correction of pectus excavatum. Clinics. 2006;61:185-186.

7. Lawson ML, Cash TF, Akers R, Vasser E, Burke B, Tabangin M, et al. A pilot study of the impact of surgical repair on disease-specific quality of life among patients with pectus excavatum. J Pediatr Surg. 2003;38:916-8

8. Dato GMA, Cavaglià M, Ruffini E, Dato A, Mancuso M, Parola A, Papalia E, Oliaro A. The seagull wing self retaining prosthesis in the surgical treatment of pectus excavatum. J Cardiovasc Surg. 1999;40:13946.
9. Haller JA, Shermeta DW, Tepas JJ, Bittner HR, Golladay ES. Correction of pectus excavatum without prostheses or splints: objective measurement of severity and management of asymmetrical deformities. Ann Thorac Surg. 1978;26:73-9.

10. Haller JA, Peters GN, Mazur D, White JJ. Pectus excavatum: a 20 year surgical experience. J Thorac Cardiovasc Surg.1970;60:376-83.

11. Knutson U. Mensurement of thoracic deformities. A new technique giving objective and reproducible results. Scand J Thorac Cardiovasc Surg. 1967;1:76-9.

12. Hümmer HP, Willital GH. Morphologic findings of chest deformities in children corresponding to the Willital-Hümmer classification. J Pediatr Surg. 1984;19:562-6.

13. Horst M, Albrecht D, Drerup B. Objective determination of the shape of the anterior chest wall using moiré topography. Method and development of dimension-free indices for the evaluation of funnel chest. Z Orthop.1885;123:357-64.

14. Rebeis EB, Samano MS, Dias CTS, Fernandez A, Campos JRM, Jatene FB, Oliveira SA. Anthropometric index for quantitative assessment of pectus excavatum. J Bras Pneumol. 2004;30:501-7.

15. Backer OG, Brüner S, Larsen V. The surgical treatment of funnel chest: initial and follow-up results. Acta Chir Scand. 1961;121:253-61.

16. Haller JA, Kramer SS, Lietman A. Use of CT scans in selection of patients for pectus excavatum surgery: a preliminary report. J Pediatr Surg.1987;22:904-6. 
17. Nakahara K, Ohno K, Miyoshi S, Maeda H, Monden Y, Kawashima Y. An evaluation of operative outcome in patients with funnel chest diagnosed by means of the computed tomogram. J Thorac Cardiovasc Surg. 1987;93:577-82.

18. Derveaux L, Clarysse I, Ivanoff I, Demedts M. Preoperative and postoperative abnormalities in chest X-ray indices and in lung function in pectus deformities. Chest. 1989;95:850-6.

19. Welch KJ. Satisfactory surgical correction of pectus excavatum deformity in childhood. J Thorac Surg. 1958;36:697-713.

20. Hellerstein Marc K, Parks Elizabeth J. Obesity and overweight. In: Greenspan FS, Gardner DG. Basic and clinical endocrinology. 7th ed. San Francisco: Lange Medical Books; 2004. p. 794-813.

21. Ravitch MM.The operative treatment of pectus excavatum. Ann Surg. 1949;129:429-44.
22. Robicsek F, Fokin A. Surgical correction of pectus excavatum and carinatum. J Cardiovasc Surg. 1999;40:725-31.

23. Daunt SW, Cohen JH, Miller SF. Age-related normal ranges for Haller index in children. Pediatr Radiol. 2004;34:326-30.

24. Robicsek F. Surgical treatment of pectus excavatum. Chest Surg Clin N Am. 2000;10:277-96.

25. Coelho MS, Stori WS, Pizarro LDV, Zanin SA, Gonçalves JL, Bergonse N. Pectus excavatum/ pectus carinatum: tratamento cirúrgico. Rev Col Bras Cir. 2003;30:249-61.

26. Ohno K, Nakahira M, Takeuchi S, Shiokawa C, Moriuchi T, Harumoto $\mathrm{K}$, et al. Indications for surgical treatment of funnel chest by chest radiograph. Pediatr Surg Int. 2001;17:591-5. 